3. Yule S, Flin R, Maran N, Rowley D, Youngson G, Paterson-Brown S. Surgeons' non-technical skills in the operating room: reliability testing of the NOTSS behavior rating system. World J Surg. 2008;32:548-56.

4. Robertson ER, Hadi M, Morgan LJ, Pickering SP, Collins G, New S, et al. Oxford NOTECHS II: a modified theatre team non-technical skills scoring system. PLoS One. 2014;9:e90320.

5. Fletcher G, Flin R, McGeorge P, Glavin R, Maran N, Patey R. Anaesthetists' Non-Technical Skills (ANTS): evaluation of a behavioural marker system. $\mathrm{Br}$ J Anaesth. 2003;90:580-8.

6. Mitchell L, Flin R, Yule S, Mitchell J, Coutts K, Youngson G. Evaluation of the scrub practitioners' list of intraoperative non-technical skills system. Int J Nurs Stud. 2012;49:201-11.
7. Dias RD, Riley W, Shann K, Likosky DS, Fitzgerald D, Yule S. A tool to assess nontechnical skills of perfusionists in the cardiac operating room. $J$ Thorac Cardiovasc Surg. 2023;165:1462-9.

8. Yule S, Rowley D, Flin R, Maran N, Youngson G, Duncan J, et al. Experience matters: comparing novice and expert ratings of non-technical skills using the NOTSS system. ANZ J Surg. 2009;79:154-60.

9. Gordon M, Darbyshire D, Baker P. Non-technical skills training to enhance patient safety: a systematic review. Med Educ. 2012;46:1042-54.

10. Riley W, Davis S, Miller K, Hansen H, Sainfort F, Sweet R. Didactic and simulation nontechnical skills team training to improve perinatal patien outcomes in a community hospital. Jt Comm J Qual Patient Saf. 2011;37: $357-64$
See Article page 1462.

\section{Commentary: Nontechnical skills for perfusionists: Assessing the ability of the person running the pump}

\author{
Mauro Cotza, MSc, ${ }^{a}$ and Mauro Lo Rito, $\mathrm{MD}^{\mathrm{b}}$
}

Nontechnical skills have become, during the past 20 years, a fundamental aspect of professional development for each member of a surgical theater team. ${ }^{1,2}$ Several works have investigated, developed, and validated tools to improve them at the surgeon, ${ }^{1,3}$ anesthesiologist, ${ }^{2}$ and nursing ${ }^{4}$ level. Dias and colleagues ${ }^{5}$ have developed a tool to assess nontechnical skills for perfusionists (Perfusionists' Intraoperative Non-Technical Skills [PINTS]), professional figures who are fundamental in the cardiac surgical theater setting. Surgeons use verbal communication to run an operation smoothly and adopt routines that help us reduce complications. The communication flows back and forward among 4 players: anesthesiologist, surgical assistant, perfusionist, and nurses. Perfusionists generally measure

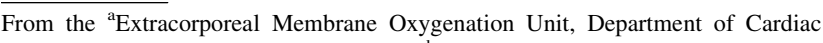
Anesthesia and Intensive Care Unit, and ${ }^{\mathrm{b}}$ Department of Congenital Cardiac Surgery, IRCCS Policlinico San Donato, San Donato Milanese, Italy.

Disclosures: The authors reported no conflicts of interest.

The Journal policy requires editors and reviewers to disclose conflicts of interest and to decline handling or reviewing manuscripts for which they may have a conflict of interest. The editors and reviewers of this article have no conflicts of interest.

Received for publication July 10, 2021; revisions received July 10, 2021; accepted for publication July 12, 2021; available ahead of print July 17, 2021

Address for reprints: Mauro Lo Rito, MD, Department of Congenital Cardiac Surgery, IRCCS Policlinico San Donato, San Donato Milanese, Italy (E-mail: mauro.1orito@gmail.com).

J Thorac Cardiovasc Surg 2023;165:1471-2

$0022-5223 / \$ 36.00$

Copyright (C) 2021 by The American Association for Thoracic Surgery

https://doi.org/10.1016/j.jtcvs.2021.07.018
}

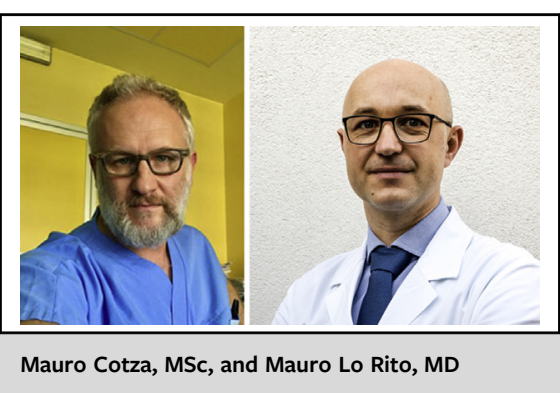

CENTRAL MESSAGE

Perfusionists' nontechnical skills are fundamental for their integration and interaction with the team. A new tool can assess them, allowing to improve training, mentorship, and work quality.

their performance in terms of compliance with clinical parameters. But in the context of a team activity, the effects of relationship skills and position as professionals represent an element of competence and evaluation. Generally, the communications flow contains indications, but surgeons often rely on nontechnical skills when immediate actions and anticipation are needed. Behavior-related aspects like decision making, task management, multidisciplinary work, and nonverbal communications are fundamental to making the team working smoothly. All these aspects are called nontechnical skills, and their assessment is often delegated to the evaluator's perceptions, which can only be objectified with sophisticated psychometric tools. The PINTS tool ${ }^{5}$ was developed by identifying 4 categories (situation awareness, decision making, task management and leadership, and teamwork and communication) and 4 
behavioral elements in each category representing the skills assessed. The tool did not undergo a formal external validation, representing a possible limitation of the tool, and it was directly tested by asking perfusionists to review and score 4 simulated cardiac surgery videos (2 poor performance and 2 good performance) according to PINTS. The PINTS tool showed moderate agreement between the different raters, indicating that, overall, the behavioral category and elements were adequate to assess the perfusionist performance.

Of note, the evidence of a common perception of behavioral adequacy was independent of working age. How PINTS may become a helpful tool remains an unanswered question. Learning from past experiences, ${ }^{1,2}$ the proper application of an evaluation system is fundamental, and becomes more important than the tool itself. Members of cardiac sugery teams need to promote detailed assessment of each professional aspect, avoiding the judgmental shadow and promoting the inclusive and educational aim of the tool. Perfusion student examination may be enhanced using PINTS to identify strengths and weaknesses of nontechnical skills, allowing tailored mentorship for better professional development. The PINTS tool may also be used when teams are not working smoothly and they desire to understand the reason and plan team affinity improvement. Finally, it may become part of the professional assessment of perfusionists, similar to surgeon or nurse evaluation.

\section{References}

1. Yule S, Gupta A, Gazarian D, Geraghty A, Smink DS, Beard J, et al. Construct and criterion validity testing of the non-technical skills for surgeons (NOTSS) behaviour assessment tool using videos of simulated operations. Br J Surg. 2018;105:719-27.

2. Boet S, Larrigan S, Martin L, Liu H, Sullivan KJ, Etherington N. Measuring non-technical skills of anaesthesiologists in the operating room: a systematic review of assessment tools and their measurement properties. $\mathrm{Br}$ J Anaesth. 2018;121:1218-26.

3. Pradarelli JC, Gupta A, Lipsitz S, Blair PG, Sachdeva AK, Smink DS, et al. Assessment of the non-technical skills for surgeons (NOTSS) framework in the USA. Br J Surg. 2020;107:1137-44.

4. Mitchell L, Flin R. Non-technical skills of the operating theatre scrub nurse: literature review. J Adv Nurs. 2008;63:15-24.

5. Dias RD, Riley W, Shann K, Likosky DS, Fitzgerald D, Yule S. A tool to assess nontechnical skills of perfusionists in the cardiac operating room. J Thorac Cardiovasc Surg. 2023;165:1462-9. 